\title{
Participação e Autonomia nos Espaços Interculturais de Saúde Indígena: reflexões a partir do sul do Brasil
}

\section{Participation and Autonomy in the Intercultural Contexts of Indian Health: reflections from southern Brazil}

Esther Jean Langdon

Doutora, Departamento de Antropologia, Centro de Filosofia e Ciências Humanas, Universidade Federal de Santa Catarina. Pesquisadora IB do CNPq.

Endereço: Caixa Postal 5104, cep. 88040-970, Florianópolis, SC, Brasil

E-mail: estherjeanbrळyahoo.com.br

\section{Eliana E. Diehl}

Doutora, Departamento de Ciências Farmacêuticas, Centro de Ciências da Saúde, Universidade Federal de Santa Catarina.

E-mail: elianadiehlळhotmail.com

\section{Resumo}

A democratização das ações e serviços de saúde no Brasil, expressa no Sistema Único de Saúde (SUS) em 1990, tem como base novas relações entre estado e sociedade. Idealisticamente, os princípios e as diretrizes do Sistema Único de Saúde, forjados ainda no Movimento de Reforma Sanitária a partir de 1976, estabelecem o papel central do usuário e deslocam o eixo do poder das macroestruturas para os níveis locais e regionais, com a ampla participação de todos os setores que compõem o cenário da saúde. No caso indígena, o Subsistema de Atenção à Saúde Indígena no âmbito do SUS foi implementado em 1999, face às históricas desigualdades e iniqüidades vividas por esses povos no Brasil. Desde a implantação do Subsistema, há sete anos, são poucas as reflexões sobre os conceitos-chaves e sua práxis em contextos interculturais: atenção diferenciada, Agentes Indígenas de Saúde e participação e controle social. Esse artigo traz uma avaliação do modelo de atenção à saúde indígena com base nesses aspectos. A partir de pesquisas realizadas no sul do Brasil, especificamente no Estado de Santa Catarina e na experiência de participação em instâncias de controle social, buscamos contribuir para a avaliação, que é exígua até o momento.

Palavras-chave: Índios sul-americanos; Política de saúde indígena; Atenção diferenciada; Interculturalidade. 


\section{Abstract}

The democratization of health actions and services in Brazil, as expressed in the National Health System (SUS) established in 1990, is based upon new relations between the State and society. Ideally, the principles and directives of SUS, also created in the Health Care Reform movement from 1976 onwards, establish the central role of the consumer and shift the axis of power from macro-institutions to local and regional levels, with broad participation of all the sectors that make up the health service field. In view of the historical inequalities and inequities experienced by the indigenous peoples of Brazil, the Subsystem of Attention to Indian Health as part of SUS was established in 1999. Since the implementation of the Subsystem seven years ago, there have been few reflections regarding the praxis of its key concepts in intercultural contexts: differentiated attention, Indian Health Agents and participation and social control. Considering these aspects, this article evaluates the model of attention to Indian health. Based on research from Southern Brazil, specifically from the State of Santa Catarina, and on the experience of participation in situations of social control, the authors hope to contribute to an evaluation of the Subsystem, which is imperative at this moment.

Keywords: South American Indians; Indian Health Policy; Differentiated Attention; Intercultural Contexts.

\section{Introdução}

A democratização das ações e dos serviços de saúde no Brasil, expressa no Sistema Único de Saúde (SUS) em 1990, tem como base novas relações entre estado e sociedade. Idealisticamente, os princípios e as diretrizes do SUS, forjados ainda no Movimento de Reforma Sanitária a partir de 1976, estabelecem o papel central do usuário e deslocam o eixo do poder das macroestruturas para os níveis locais e regionais, com a ampla participação de todos os setores que compõem o cenário da saúde.

No caso indígena, nove anos após a criação do SUS, o Decreto nº 3.156 (Brasil, 1999a) e a Lei no 9.836 (Brasil, 1999b) determinaram as condições de assistência à saúde dos povos indígenas e o Subsistema de Atenção à Saúde Indígena no âmbito do SUS, respectivamente, tendo em vista as históricas desigualdades e iniqüidades vividas por esses povos no Brasil. Posteriormente, essa legislação regulamentou a Política Nacional de Atenção à Saúde dos Povos Indígenas (PNASPI), integrante da Política Nacional de Saúde (Brasil, 2002).

O Subsistema de Atenção à Saúde Indígena é organizado por meio dos Distritos Sanitários Especiais Indígenas (DSEIs), compostos de postos de saúde dentro das Terras Indígenas, que contam com o trabalho dos Agentes Indígenas de Saúde (AIS) e dos Agentes Indígenas de Saneamento (Aisan); pelos pólos-base, que incluem as Equipes Multiprofissionais de Saúde Indígena (EMSI); e pelas Casas do Índio (Casai), que apóiam os serviços de média e alta complexidade referenciados na rede do SUS (Brasil, 2004). Em algumas realidades, como no sul do Brasil, há postos de saúde nas aldeias que incluem permanentemente a EMSI. A Fundação Nacional de Saúde (Funasa) é o órgão encarregado pela coordenação, normatização e execução das ações de atenção à saúde indígena e os estados, municípios, organizações governamentais e não-governamentais (ONGs) podem atuar complementarmente na execução das ações (Brasil, 2004).

Para a realização das ações e serviços de saúde aos povos indígenas, foram definidos recursos financeiros suplementares àqueles já definidos no SUS, sendo as principais fontes (Diehl e col., 2003): 1- o "Fator de Incentivo de Atenção Básica aos Povos Indígenas", que é um componente do Piso da Atenção Básica Variá- 
vel, transferido do Fundo Nacional de Saúde aos Fundos de Saúde do Distrito Federal e dos Municípios, mediante a adesão e a implementação das ações a que se destinam e desde que constantes no respectivo Plano de Saúde (Brasil, 1999c; Brasil, 2007); 2- o "Fator de Incentivo para a Assistência Ambulatorial, Hospitalar e de Apoio Diagnóstico a População Indígena”, destinado para os estabelecimentos hospitalares que considerem as especificidades da assistência à saúde das populações indígenas e que ofereçam atendimento a elas, em seu próprio território ou região de referência (Brasil, 1999c); 3- os convênios celebrados entre a Funasa e estados, municípios e/ou ONGs para a atenção básica.

O Subsistema de saúde indígena, que deve garantir a universalidade, a integralidade, a eqüidade e a participação comunitária, instituiu ainda o princípio da atenção diferenciada, que deve levar em conta "as especificidades culturais, epidemiológicas e operacionais desses povos. Assim, dever-se-á desenvolver e fazer uso de tecnologias apropriadas por meio da adequação das formas ocidentais convencionais de organização de serviços" (Brasil, 2002, p. 6), ou seja, esse princípio é definido como uma diferenciação na qualidade dos serviços. Também a partir da criação do Subsistema, o AIS ganha destaque como membro das comunidades que deve servir como mediador entre os saberes tradicionais e os conhecimentos e recursos da medicina ocidental. Outro aspecto relevante trazido pelo novo modelo de atenção é a participação indígena, na qual os diversos povos tiveram que se organizar na forma de Conselhos de Saúde para o exercício do controle social.

Desde os sete anos da implantação do subsistema, são poucas as reflexões sobre a atenção diferenciada, o papel dos agentes indígenas de saúde e a participação e controle social, podendo ser citados os trabalhos de Garnelo (2001), Erthal (2003), Oliveira (2002 e 2005), Garnelo e Sampaio (2003), Garnelo e col. (2003), Diehl e col. (2003), Marques (2003), Langdon (2004), Mendonça (2005), Bittencourt e col. (2005), Marinho (2006) e Langdon e col. (2006).

Esse artigo traz uma reflexão crítica do modelo de atenção à saúde indígena implementado no final de 1999 com base nos aspectos acima citados. A partir de pesquisas realizadas no sul do Brasil, especificamente no Estado de Santa Catarina, e na experiên- cia de participação em instâncias de controle social, buscamos contribuir para a avaliação, que é exígua até o momento.

\section{Conceituação de "Atenção Diferenciada" na Política de Saúde Indígena}

O princípio de atenção diferenciada no qual se refere a situação multicultural de ações e serviços de saúde indígena foi expressa inicialmente na I Conferência Nacional de Proteção à Saúde do Índio, realizada em 1986. A partir da reforma sanitária, a Conferência objetivava avaliar a situação de saúde dos índios e criar uma política efetiva para os povos indígenas. Entre as recomendações (Krenak e col., 1988) relevantes para pensar a atenção diferenciada, citamos duas: 1) garantir a participação política das nações indígenas na formulação, no planejamento, na gestão, na execução e na avaliação das ações e dos serviços de saúde; 2) assegurar o respeito e o reconhecimento das formas diferenciadas das nações indígenas no cuidado com a saúde. Essas recomendações vêm sendo desde então incorporadas nas Conferências de Saúde Indígena, bem com na legislação geral para a saúde e na específica à saúde indígena.

Em 200o, foi lançada a primeira edição da Política Nacional de Atenção à Saúde dos Povos Indígenas, sendo a segunda edição de 2002. Em referência às práticas indígenas de auto-atenção à saúde, o documento reconhece "a eficácia de sua medicina e o direito desses povos à sua cultura" (Brasil, 2002, p. 13. Grifos das autoras). Adiante afirma: "O princípio que permeia todas as diretrizes da Política Nacional de Atenção à Saúde dos Povos Indígenas é o respeito às concepções, [aos] valores e [às] práticas relativos ao processo saúde-doença próprios a cada sociedade indígena e a seus diversos especialistas" (Brasil, 2002, p. 18). Em outra parte, a base simbólica e a eficácia dos sistemas tradicionais são ressaltadas:

Os sistemas tradicionais indígenas de saúde são baseados em uma abordagem holística de saúde, cujo princípio é a harmonia de indivíduos, famílias e comunidades com o universo que os rodeia. As práticas de cura respondem a uma lógica interna de cada comunidade indígena e são o produto de sua relação 
particular com o mundo espiritual e os seres do ambiente em que vivem. Essas práticas e concepções são, geralmente, recursos de saúde de eficácias empírica e simbólica, de acordo com a definição mais recente de saúde da Organização Mundial de Saúde (Brasil, 2002, p. 17).

Para adequar as ações dos serviços de saúde, o documento aponta para três vertentes: 1) a capacitação dos recursos humanos visando à preparação para a atuação em contextos interculturais, por meio de cursos de atualização/aperfeiçoamento/especialização; 2) a articulação com os sistemas tradicionais indígenas de saúde; 3) a formação e a capacitação de Agentes Indígenas de Saúde como uma estratégia que visa favorecer a apropriação, pelos povos indígenas, de conhecimentos e recursos técnicos da medicina ocidental, "não de modo a substituir, mas de somar ao acervo de terapias e outras práticas culturais próprias, tradicionais ou não" (Brasil, 2002, p. 16. Grifos das autoras).

Em 2004, a Portaria $n^{0} 70$ reafirma estas três diretrizes de atuação, utilizando a palavra "integrar as ações da medicina tradicional" (Brasil, 2004, p. 2. Grifo das autoras) em vez de "articular". Essa substituição tem implicações que serão exploradas posteriormente.

\section{O Papel dos AIS na Atenção Diferenciada}

A inclusão dos AIS nas ações e nos serviços de atenção primária à saúde indígena ocorreu a partir da década de 1980, seguindo a tendência verificada para a população não-indígena, conforme recomendou a Organização Mundial da Saúde em 1978, na Declaração de Alma-Ata. Para maiores detalhes sobre essa inserção, em especial no que se refere à definição oficial do papel dos AIS e à capacitação, ver Langdon e col. (2006).

O AIS não é visto como um mero distribuidor de medicamentos, mas como o "elo de ligação entre as sociedades indígenas e o sistema de saúde diferenciado". Ao AIS tem sido atribuída uma função estratégica fundamental "como agente de transformação, na busca da melhoria da qualidade de vida e autonomia de seus respectivos povos" (Brasil, 1996, p. 8).
A partir da criação dos Distritos Sanitários, em 1999, e do aumento significativo no orçamento designado para a saúde indígena, o número de AIS capacitados e contratados para trabalhar com as Equipes Multiprofissionais de Saúde Indígena (EMSIs) nas Terras Indígenas aumentou, no intuito de desenvolver formas de atenção diferenciada e de incrementar a participação dos índios nos serviços de saúde, bem como contribuir para a qualidade dos serviços em um contexto intercultural. Com objetivos semelhantes, o cargo de Agente Indígena de Saneamento (Aisan) foi criado em 2004. Dos 2.000 AISs estimados em 2000, o número subiu para $5.106 \mathrm{em} \mathrm{2006}{ }^{1}$. No mesmo ano, 1.348 AISANs trabalhavam com as EMSIs.

Para subsidiar uma análise da qualidade dos serviços de saúde em contextos interculturais, bem como o controle social, e avaliar a operacionalidade da atenção diferenciada na atenção primária dos povos indígenas, foi organizada uma equipe no final de 2003 para pesquisar $^{2}$ o papel do AIS entre os Kaingang da Terra Indígena (T.I.) Xapecó e da T. I. Laklãnõ, Santa Catarina, no âmbito do Distrito Sanitário Especial Indígena Interior Sul. O projeto visava ao acompanhamento e à análise do papel do AIS na atenção básica, com ênfase na sua formação, nas visões dos AISs acerca da atenção diferenciada à saúde e nas ações delegadas a eles sob as perspectivas da organização dos serviços e dos próprios AISs, bem como as dificuldades enfrentadas. Os AISANs foram incluídos na pesquisa quando possível, porém, devido à sua inserção recente na EMSI, a contribuição deles para as discussões foi mínima.

Para fins comparativos com outros contextos, é importante lembrar que a situação dos índios do sul do país, diferente da região amazônica brasileira, é marginal em termos sociais, espaciais e econômicos. Podem ser considerados os pobres entre as populações mais favorecidas que rodeiam suas Terras Indígenas e, como conseqüência sofrem de doenças endêmicas e carenciais e suas condições sanitárias são insatisfatórias. No caso de Santa Catarina, seus vizinhos em geral são colonos de origem alemã e italiana e/ou grandes fazendeiros, caracterizados por seus preconceitos em relação às populações indígenas. Vale ressal-

1 Conforme Departamento de Saúde Indígena/Funasa, Comunicação pessoal, 2006.

2 Ver Langdon e col. (2006) para informações detalhadas da pesquisa. 
tar que muitos dos antepassados dessa vizinhança eram bugreiros, que "caçavam" os índios no início do século XX (Santos, 1997). Os índios nessa região têm contato intenso com a sociedade envolvente e suas vidas cotidianas manifestam a apropriação de objetos, valores e práticas da cultura popular, incluindo as de alimentação, de saúde e de religião, porém, sua identidade étnica ainda tem raízes na cultura autóctone e representa uma visão de mundo altamente diferenciada daquela existente entre os colonos e fazendeiros que os cercam.

\section{O AIS em Santa Catarina}

A despeito da importância e da centralidade delegadas ao papel do AIS nos documentos da Funasa, a pesquisa em Santa Catarina demonstrou que a realidade é bastante diferente, apontando várias limitações que não permitem a realização de um serviço básico que poderia ser caracterizado como atenção diferenciada. Aspectos definidos pelos documentos oficiais como fundamentais à formação e à atuação dos AISs estão sem resolução na prática, ou seja, poucos recebem capacitação, seu papel é mal-definido e ambíguo, a seleção dos agentes é determinada em grande parte por processos políticos internos e externos, a relação com os profissionais de saúde é hierarquizada e burocratizada, e a noção de atenção diferenciada é pouco compreendida tanto pelos AISs como pelos outros profissionais da EMSI.

\section{Alta rotatividade, seleção e capacitação dos AISs}

Nossa pesquisa documental e de campo observou uma alta rotatividade dos AISs, com poucos que permaneciam no cargo desde a implantação do DSEI Interior Sul. Essa rotatividade estendeu-se durante todo o período de pesquisa de campo em escalas consideráreis. Entre maio e julho de 2004, por exemplo, verificamos que praticamente 50\% das equipes da T. I. Xapecó haviam sido mudadas. Tanto os AISs quanto os demais membros das EMSIs foram constantemente substituídos, ou por questões políticas, ou por não se adequarem ao ritmo, dinâmicas e pressões que marcam o cotidiano do exercício de suas funções.

As causas da alta rotatividade dos AISs estavam relacionadas em parte às formas de contratação e de seleção dos AIS, ambas marcadas por processos políticos internos e externos à T.I. Os recursos financeiros para a contratação tinham origem no convênio com a Funasa ou no repasse do Fundo Nacional de Saúde aos Fundos Municipais de Saúde. Dessa forma, a responsabilidade de contratação podia ser do município e de uma ONG indígena, caso da T.I. Xapecó em 2004: uma parcela dos AISs do mesmo pólo-base era empregada pelo município, via Programa Saúde da Família (PSF), e a outra pela ONG. Essa situação gerava uma certa divisão entre os AISs em relação às atividades e lealdades. Não obstante, em ambos os casos, a seleção dos AISs não passava por um processo de escolha democrática, apesar de esforços dos técnicos locais para garantir o cumprimento das diretrizes que indicam a contratação dos profissionais que formarão as EMSIs.

No caso das relações internas da comunidade, a escolha do AIS dependia das alianças e facções, do parentesco, da liderança ou da religião. Esses aspectos formam parte da própria dinâmica ligada às particularidades culturais da organização social e suas redes de obrigações e favores (ver Garnelo e col., 2004, para uma descrição sobre o impacto de processos semelhantes entre os Baniwa do Alto Rio Negro). No caso de contratação por municípios, ela acabava, muitas vezes, sendo influenciada por forças políticas locais, marcadas por clientelismos e faccionalismos partidários. Pressupomos que essa tendência não constitui característica isolada, mas sim advém de um contexto estrutural inerente à própria dinâmica política nacional, observada especialmente em municípios de pequeno porte, cujo controle social e presença do poder público federal são restritos. Essa característica agrava-se em municípios limítrofes às terras indígenas por vários motivos e naturezas diversas.

Há de se considerar que 2004 possa ter sido um ano atípico nas sociedades pesquisadas, por se tratar de ano de eleições municipais, responsável, portanto, pelas turbulências críticas e crônicas observadas na esfera de atuação do subsistema. Vários AISs relataram, por exemplo, ser obrigados a trabalhar como "cabos eleitorais" dos candidatos a prefeitos e a vereadores, muitas vezes sentindo-se melindrados, pois traíam suas fidelidades ideológicas ou familiares que, em alguns casos, eram contrárias à dos políticos e/ou às lideranças que mantinham seus empregos.

A alta rotatividade dos profissionais de saúde nas EMSIs não é uma particularidade somente desse DSEI, mas uma realidade nos outros 33 DSEIs do país 
(Garnelo e col., 2003), e ela tem um impacto preocupante na formação das equipes. A capacitação de forma contínua é um pilar da preparação dos membros das EMSIs para o trabalho. Não obstante, observou-se que até o período pesquisado poucos cursos haviam sido oferecidos pela Funasa para os AISs e para os outros profissionais. Esse fato, somado à alta rotatividade, resultava em despreparo significativo para o serviço.

Especificamente em relação aos AISs em Santa Catarina, identificamos que a maioria deles não recebeu qualquer curso de formação. Entre 1999 e 2004, identificou-se que somente dois cursos foram oferecidos pelo gestor e que um número mínimo dos AISs trabalhando em 2004 tinha participado deles. A maioria manifestou que uma orientação ao trabalho era inexistente no início da contratação, sendo a necessidade de cursos de formação constantemente observada durante a pesquisa de campo. A sua ausência era indicada como motivo de insegurança no exercer cotidiano de suas práticas de atenção à saúde, assim como fonte de descrédito na sua eficácia diante da população por eles atendida. Por esforço próprio, alguns estavam realizando cursos particulares de técnico de enfermagem ou concluindo o ensino médio.

Além da escassez de cursos de capacitação, pode ser questionada também a contribuição potencial para a atenção diferenciada dos que têm sido oferecidos pela Funasa. Logicamente, o conteúdo programático de sua formação deve ser pensado de forma cautelosa para que não se limite à aprendizagem puramente de cunho biomédico, mas sim que incorpore elementos próprios e pertencentes aos sistemas de atenção à saúde encarnados nas culturas e práticas locais. É necessário sempre ter em vista a neutralização da construção de novas hierarquias de conhecimentos no campo da atenção à saúde, já que o modelo biomédico é preponderante e hegemônico frente a outros que podem também apresentar grande eficácia. Uma análise dos Módulos para "Educação Profissional Básica para Agentes Indígenas de Saúde" elaborados pela FUNASA (Brasil, 2005a, 2005b, 2005c, 2005d, 2005e, 2005f) indica que o treinamento dos AISs, quando existe, está orientado basicamente à aprendizagem de práticas biomédicas.

\section{Atividades, competências e relação com a equipe}

As atividades delegadas aos AISs são amplas e podem ser agrupadas em quatro funções gerais: 1) Visitas domiciliares; 2) Educação e orientação sobre cuidados de saúde e informações sobre o sistema de saúde e seu funcionamento, incluindo os programas especiais de saúde; 3) Preenchimento dos vários formulários, como ficha de visitas com assinatura de membro da família, relatórios mensais de suas atividades e outros solicitados pela equipe; e 4) participação nas atividades de controle social.

Em Santa Catarina, os cuidados de atenção primária são delegados ao auxiliar ou ao técnico de enfermagem, sendo os AISs proibidos de realizar tarefas mínimas, como tomar a temperatura, medir a pressão arterial e aplicar injetáveis. Porém, podem recomendar tratamentos considerados fitoterapêuticos ou o uso de soro caseiro, aprendidos com os cursos da Pastoral da Saúde. Em algumas tarefas, há ambigüidade de competências, por exemplo, está prescrito na “agenda de atividades" dos AIS "fazer o controle mensal de peso e da altura das crianças e das gestantes”. Contudo, esta tarefa quem costumava fazer era a auxiliar de enfermagem. Na lógica da organização profissional, o AIS é membro de uma equipe hierarquizada em conhecimentos e funções.

Espera-se que o AIS, nas suas visitas regulares, atue como elo de comunicação e educação entre as famílias e os demais membros da equipe. Assim, ele deve anotar e comunicar necessidades de consultas e riscos à saúde, acompanhar a administração dos medicamentos, transmitir informações sobre consultas e programas de saúde e acompanhar os doentes necessitando de serviços na rede de referência do SUS. As visitas domiciliares e seu registro nos formulários tornavam as atividades ambíguas e sem justificativa clara para os agentes. Diante das proibições de realizar cuidados de atenção primária, expressaram o enfrentamento de expectativas contraditórias por parte da EMSI e da comunidade. Assim, percebiam que eram cobrados pela comunidade no sentido de tomarem decisões que não estavam no rol de suas funções ou para as quais não foram preparados adequadamente. Como nos afirmou um AIS, "os índios pensam que somos médicos”. Também, os AIS se perceberam culpabilizados pelos membros da comunidade em relação às falhas dos serviços do restante da EMSI ou quando o médico não aparecia numa consulta marcada pelo agente.

Nossas observações de campo constataram que muitas visitas foram realizadas de uma maneira pon- 
tual, às vezes somente para conseguir a assinatura da família e, em alguns casos, as visitas não foram realizadas em todas as casas, apenas aquelas em que se sabia haver alguém doente. Outros fatores que influenciaram a regularidade das visitas foram: o quadro de faccionalismo político existente, que fazia com que o AIS não visitasse regularmente as famílias rivais; e as distâncias a serem percorridas até as casas (é importante lembrar que os AIS não tinham transporte próprio).

0 preenchimento dos formulários das atividades realizadas se tornou a atividade principal de supervisão e os AIS manifestaram frustração com os inúmeros formulários e planilhas que precisavam completar. Idealmente, o trabalho dos AISs deve ser acompanhado e supervisionado, com treinamento contínuo. $\mathrm{Na}$ ausência de acompanhamento, as reuniões de supervisão têm como foco central os formulários a serem preenchidos pelos AIS mensalmente, eliminando o tempo dos AISs com seus supervisores que deveria ser dedicado a uma discussão que efetivamente trataria dos problemas enfrentados pelos agentes no seu dia-a-dia. Os AISs reclamaram que os outros membros da EMSI não os escutavam e assim não conheciam os problemas da comunidade. Quando questionados diretamente sobre a função dos formulários, alguns acreditavam que eles não eram lidos pelo resto da equipe e que não tinham retorno, prático ou reflexivo, a respeito dos dados levantados. Por isso, acusaram que, atualmente, ao contrário do passado, a equipe "não sabe lidar com o índio, não conhece a nossa realidade". Outros interpretaram os formulários como instrumentos de controle por parte do resto da equipe e do gestor, não os visualizando como parte do sistema de informação em saúde. Essa interpretação, porem, não está equivocada: o preenchimento dos formulários, em certa medida, torna-se um controle burocrático sobre as atividades dos AISs, sem outras fontes de avaliação ou acompanhamento.

Houve avaliação por parte dos AIS sobre o exercício de habilidades específicas de outros profissionais da equipe. Eles distinguiam, segundo sua percepção, os profissionais de saúde que estavam ao lado dos índios e os que demonstravam preconceito, por exemplo, uma AIS citou um enfermeiro que manifestou uma atitude de moralização e superioridade quando argumentou contra o uso do fogo de chão nas casas indígenas, acusando-os de sujos: "O índio não é sujo; to- dos nós têm roupa limpa no varal”. Nossas observações das interações entre os AISs e os profissionais indicaram momentos de tensão entre eles, nos quais os agentes foram colocados em papel de subordinado. As relações hierárquicas e desiguais marcam os AISs e outros membros da equipe e sua administração - em sua maioria composta de não-indígenas-, que por sua vez estão inseridos em um contexto de relações históricas de intolerância étnica. Há ainda que se salientar as especificidades socioculturais indígenas diante dos não-indígenas, marcadamente compostas de colonos de origem germânica e italiana, cujo ethos é fortemente embebido de ideologias que sustentam a austeridade, o trabalho árduo e as famílias nucleares.

Atrelada a essas acusações e conflitos, está a pressão exercida pelos gestores para que os AISs trabalhem todos os dias, oito horas por dia, impondo uma agenda, um ritmo e uma relação com o trabalho que não condizem com "o sistema indígena". Por sua vez, os AISs, que recebem em média um salário mínimo por mês, sabem que os membros da equipe com maior formação escolar e acadêmica têm salários infinitamente maiores que os seus e trabalham vertiginosamente menos horas do que eles nos Postos de Saúde. Essa posição desfavorável dos AISs em relação aos outros profissionais encontra paralelo na situação vivenciada pelos Agentes Comunitários de Saúde (ACSs), como apontaram Nunes e col. (2002). Para esses autores, a discrepância nos valores dos salários entre ACSs, médicos e enfermeiros e o aumento das tarefas e responsabilidades quando os ACSs foram incluídos nas equipes do PSF, sem aumento salarial, geraram nos agentes um sentimento de desvalorização do trabalho, nitidamente presente entre os AISs participantes desse estudo.

Essa pesquisa confirmou observações feitas em outras pesquisas sobre a ambigüidade do papel do AIS, tanto para os agentes quanto para a comunidade e os profissionais de saúde. Apesar de ser definido como um representante da comunidade que participa dos serviços e das atividades de controle social, eles, como membros contratados da equipe, percebem que a Funasa é seu chefe, criando uma situação de conflito de papel. Demonstrou-se ainda que há uma falta de receptividade por parte da equipe e do gestor para a contribuição dos AISs nos processos de participação 
e controle social. À medida que a falta de comunicação entre os AISs e o resto da equipe aumenta, como no caso de Santa Catarina, mais surgem ambigüidades e conflitos.

Outra ambigüidade é a ausência de reconhecimento profissional da categoria de Agente Indígena de Saúde. Os participantes da pesquisa expressaram essa situação por meio da frustração pela falta de reconhecimento dos membros da EMSI e ainda mais pelos profissionais de saúde na rede de referência do SUS. Oliveira (2002, 2005) e Mendonça (2005) apontaram este problema no Xingu, apesar dos AISs lá receberem cursos de capacitação e sua contribuição na atenção primária ser reconhecida pelos profissionais. Segundo Oliveira, a inserção institucional dos AISs é incipiente e conflituosa. Uma solução para isso tem sido formar os AISs como auxiliares de enfermagem, categoria profissional que se assemelha mais ao perfil de AIS (Mendonça, 2005). No caso de Santa Catarina, os AISs realizando ou com esperanças de realizar cursos de Auxiliar de Enfermagem, perceberam nesta maneira uma forma de garantir seu reconhecimento institucional e também a segurança do emprego.

\section{Mediação entre saberes e atenção diferenciada}

Como visto pela análise acima, o papel do AIS como mediador entre as práticas indígenas e os serviços biomédicos é uma visão pouca realista. 0 tema da atenção diferenciada não foi espontaneamente levantado nas nossas entrevistas, nem com os profissionais de saúde nem com os AISs. As respostas dos AISs quando perguntamos nos grupos focais especificamente sobre o significado da atenção diferenciada, indicaram que para eles o conceito refere ao aspecto de acesso universal e igualdade na qualidade de serviços. Alguns afirmaram que "O índio não tem que esperar em fila mais", justificando um status especial diante dos serviços de saúde. Ao perguntarmos especialmente sobre os saberes tradicionais de saúde, a maior parte dos AISs afirmou ter pouco conhecimento de práticas indígenas e referiu os mais velhos, freqüentemente as mulheres, como detentoras desses "segredos". Reclamaram ainda que elas atendem os doentes, mas não revelam seus segredos.

É necessário ainda apontar que dentro do universo de práticas de atenção e cuidado em saúde, encontra-se entre os Kaingang e Xokleng uma forte presen- ça do universo religioso (Veiga, 2004; Wiik, 2001, 2004). Entre os Kaingang, há muitas práticas terapêuticas cuja origem está no catolicismo popular, muitas vezes amalgamado ao saber e às práticas xamânicas, assim como práticas terapêuticas elencadas pelo universo cristão Pentecostal, massivamente presente nas últimas duas décadas na T.I. Xapecó. Entre os Xokleng, a interface entre saúde e religião praticamente se reduz ao universo Pentecostal. Em termos abstratos e analíticos, podemos afirmar que essas práticas fazem parte do universo de conhecimento e práticas de cuidado à saúde tidos como "tradicionais" ou alternativos, que são concomitantes ao biomédico.

Pesquisas realizadas ao longo dos anos entre os povos Jê do Sul têm apontado para a existência de vários tipos de especialistas em cura e que continuam atuando de forma intensa (Oliveira, 1996, 1997; Haverroth, 1998; Crépeau, 2002; Rosa, 2005). A diversidade de conhecimento e especialistas é bastante variável, devido à incorporação de conhecimentos exógenos às práticas de cura. 0 trabalho desses especialistas e de outras pessoas que também têm certa atuação nas questões de saúde reflete uma cosmologia complexa, que atualmente pode incorporar aspectos religiosos das igrejas existentes nas T.I., dependendo da experiência do indivíduo. 0 papel das plantas nesse universo cosmológico é fundamental e o conhecimento sobre elas também é diversificado, representando uma forte incorporação das plantas da medicina popular brasileira. A diversidade de especialistas e práticas se interpõe, resultando um sincretismo no qual os valores são reelaborados pelo grupo e identificados como próprio deles.

Como exemplo, por incentivo da Pastoral da Saúde local (ligada à Conferência Nacional dos Bispos do Brasil), as ervas medicinais vinham ganhando força entre os Kaingang nas últimas duas décadas. Em 2004, o Posto de Saúde da Aldeia Sede contava com uma horta medicinal e um pequeno laboratório de processamento de plantas medicinais, sob o comando de uma técnica-atendente com vários anos de experiência. Essa atendente indígena, integrante da EMSI, além de ser considerada "especialista" pelos Kaingang e atender pacientes dentro do Posto, também treinava outros indígenas sobre o processamento de chás, pomadas e infusões. Esse conhecimento era replicado por toda a comunidade por meio dos AISs e 
agentes de saúde voluntários da Pastoral. Atrelado ao uso desses produtos, havia toda uma construção ideológica da sociedade nas quais os mesmos eram instrumentos de "resgate da cultura médica indígena tradicional". Infelizmente, em 2006 encontramos a "farmácia do mato" praticamente abandonada, o laboratório desabastecido e a especialista em vias de retornar à sua função original, a de atendente de dentista do Posto de Saúde da aldeia Sede ${ }^{3}$.

\section{o Controle Social no Subsistema de Saúde Indigena}

Nas novas relações entre a sociedade e o estado, o controle social sobre ações e recursos do estado toma dimensões importantes, configurado na participação popular. A participação social em saúde, definida em Machado (1986, p. 299) como "o conjunto de intervenções que as diferentes forças sociais realizam para influenciar a formulação, a execução e a avaliação das políticas públicas para o setor saúde”, está institucionalizada por meio dos conselhos de saúde e das conferências de saúde.

A participação social e os conselhos e conferências de saúde são regulamentados pela Lei $n^{0} 8.142 /$ 1990 e pela Resolução no 333/2003 (Brasil, 2003). Segundo a Lei $n^{0} 8.142 / 1990$, o conselho de saúde tem caráter permanente e deliberativo, composto de representantes do governo, prestadores de serviços, profissionais de saúde e usuários, atuando na formulação de estratégias e no controle da execução da política de saúde na instância correspondente, inclusive nos aspectos econômicos e financeiros. A Resolução $n^{0}$ 333/2003 amplia a definição de conselho de saúde como o "órgão colegiado, deliberativo e permanente do SUS em cada esfera de governo", salientando que o "processo bem-sucedido de descentralização tem determinado a ampliação dos conselhos de saúde que ora se estabelecem também em conselhos regionais, conselhos locais, conselhos distritais de saúde, incluindo os conselhos distritais sanitários de saúde indígena” (Brasil, 2003, p. 4. Grifos das autoras).

Com a criação e a operacionalização do subsistema de saúde indígena (Lei n 9.836/1999 e Decreto nº 3.156/1999), a participação indígena em organismos colegiados, como Conselhos Municipais, Estaduais e Nacional de Saúde, Conselhos Distritais de Saúde Indígena (Condisi) e Conselhos Locais de Saúde Indígena, é assegurada por direito. Chama a atenção que segundo o Decreto $n^{0}$ 3.156/1999, reiterado pela Portaria $\mathrm{n}^{0}$ 70/GM/2004, aos Condisi compete somente aprovar e acompanhar a execução do Plano Distrital de Saúde Indígena, acompanhar as ações dos conselhos locais de saúde indígena e exercer o controle social das atividades de atenção à saúde indígena, não especificando o seu papel enquanto proponentes de políticas de saúde para os povos indígenas. Isso contraria a Resolução no ${ }^{0} 33 / 2003$, que aponta na sua terceira diretriz a "participação da sociedade organizada, garantida na Legislação, torna os Conselhos de Saúde uma instância privilegiada na proposição, discussão, acompanhamento, deliberação, avaliação e fiscalização da implementação da Política de Saúde, inclusive em seus aspectos econômicos e financeiros" (Brasil, 2003, p. 4-5. Grifo das autoras).

Com a criação de 34 Distritos Sanitários Especiais Indígenas a partir de 1999, foram estabelecidos os respectivos Condisi e inúmeros Conselhos Locais espalhados pelas Terras Indígenas. Os Condisi, que seguem a lógica de paridade estabelecida para os Conselhos Municipais, Estaduais e Nacional de Saúde, podem ser considerados "os novos espaços de construção de identidades sociais e de direitos, (...) vale dizer, a constituição e dinâmica dos novos espaços da política, que não aqueles tradicionalmente reconhecidos" (Cohn, 2003, p. 10). Cohn ainda defende que esse novo fenômeno deveria "constituir, de certa forma, a agenda de preocupação dos cientistas sociais” (2003, p. 10), no sentido de buscar identificar e compreender esses novos espaços.

A reflexão aqui apresentada sobre o controle social na saúde indígena está baseada na experiência de participação em um Condisi (Interior Sul), na interpretação de atas de reuniões desse Conselho, bem como na participação como membro na Comissão Intersetorial de Saúde Indígena (CISI), Comissão que faz parte do Conselho Nacional de Saúde.

Vale salientar que muito recentemente (Brasil, 2006a) deixaram de existir os DSEIs Interior Sul (que abrangia as Terras Indígenas localizadas nas regiões

3 Veja Garnelo e col. (2004) para uma análise das complexidades das experiências em “medicina tradicional” na região do Rio Negro. 
mais a oeste dos Estados do Rio Grande do Sul, Santa Catarina, Paraná e São Paulo) e Litoral Sul (que incluía as Terras Indígenas localizadas no litoral dos Estados do Rio Grande do Sul, Santa Catarina, Paraná, São Paulo e Rio de Janeiro), dando lugar aos DSEIs SulSudeste (que compreendem a totalidade das Terras Indígenas limitadas nos Estados do Rio Grande do Sul, Santa Catarina, São Paulo e Rio de Janeiro) e DSEI Paraná (que inclui todas as Terras Indígenas do Estado do Paraná).

O impacto político e operacional/organizacional dessas mudanças ainda não pode ser medido, e as considerações aqui feitas a respeito do Condisi Interior Sul (Condisi Insul) não devem ser apreciadas como um momento do passado recente na história indígena, mas como parte de um processo que vem sendo paulatinamente construído, independente da constituição de novos DSEIs e Conselhos Distritais.

\section{O DSEI Interior Sul e o Condisi Insul}

O DSEI Interior Sul, com população indígena estimada em torno de 30 mil pessoas, pertencentes às etnias Kaingang, Guarani, Xokleng, Krenak e Terena, tinha sede nas instalações da Coordenação Regional/ Funasa-SC, em Florianópolis (o novo DSEI Sul-Sudeste mantém a sede em Florianópolis) e os pólos-base eram localizados em Bauru (SP), Londrina (PR), Guarapuava (PR), Chapecó (SC), José Boiteux (SC) e Passo Fundo (RS). Desde a criação desse DSEI até agosto de 2006, cerca de cinco coordenadores foram indicados, todos não-indígenas.

O Condisi Insul foi instituído em novembro de 2000 e contava, em meados de 2006 , oficialmente com 40 membros titulares (20 índios e 20 membros das instituições gestoras, prestadoras de serviço e profissionais de saúde). Nesse período, realizou nove reuniões ordinárias e uma extraordinária: uma em 2000, três em 2001, três em 2002, sendo uma extraordinária, uma em 2003, uma em 2004, uma em 2005 e nenhuma em 2006. Todas as reuniões foram em Florianópolis.

\section{Representatividade e rotatividade}

As reuniões do Condisi Insul revelavam os conflitos gerados por uma ambigüidade de papéis dos seus membros, não ficando claro, muitas vezes, quem eles estavam representando. Alguns indígenas eram contratados pela Funai ou Funasa, mas atuavam no Con- selho como representantes dos usuários, por exemplo, em uma reunião, um índio perguntou: "Eu trabalho para Funai e sou índio. Quem eu represento?” Nesse sentido, ao mesmo tempo que deveriam trazer para a discussão as demandas das comunidades que representavam, suas atuações poderiam ser vigiadas (e cobradas) pelas instituições empregadoras.

Outro dado importante é que nem todas as etnias que faziam parte desse Distrito estavam representadas no Condisi. Em mais de uma reunião, discutiu-se sobre a falta de vaga para conselheiro Guarani, já que índios dessa etnia, mesmo em minoria, viviam nesse DSEI, em especial em Santa Catarina e Rio Grande do Sul. Ainda sobre a representatividade indígena, para outro índio, que vinha fazendo constantes solicitações de melhorias em sua área, "sua representatividade nada vale diante da comunidade, visto que passa ano e nada de construir o posto de saúde".

Em relação à representação não-indígena, embora na composição dos conselhos de saúde (Brasil, 2003) esteja garantida a participação de gestores e prestadores de serviços (na proporção de $25 \%$ ) e de trabalhadores de saúde ( $25 \%$ ), no caso desse Conselho Distrital boa parte do seu conjunto estava diretamente envolvida com a gestão e a operacionalização do DSEI. É necessário ainda salientar que entre os três conselheiros representando os trabalhadores (em torno de $8 \%$ do total do Condisi), dois eram servidores da Funai ou da Funasa, ocupando cargos de chefias administrativas, portanto, a representação não-indígena estava comprometida, pois, sendo a maioria vinculada à gestão e à prestação de serviços no Distrito, ela se tornava fiscal de si própria, o que nos faculta questionar a efetividade do Conselho.

Porquanto o DSEI e o Condisi envolviam quatro Estados, com as várias representações institucionais (Coordenações Regionais da Funasa, Administrações Regionais da Funai e Secretarias de Estado da Saúde), muitas vezes as reuniões eram marcadas por conflitos de competências. No início do funcionamento do DSEI, os embates entre Secretaria de Estado da Saúde (SES) e Funasa ficaram bastante evidentes, em especial na questão de recursos humanos (Agente Indígena de Saúde versus Agentes Comunitários de Saúde e enfermeiros da SES) e na falta de informações sobre saúde (Sistema de Informação em Saúde Indígena/Siasi versus Bancos de Dados oficiais do SUS). 
O modelo de organização e funcionamento dos Condisi, que na teoria deve reproduzir os conselhos de saúde não-indígenas, não condiz com a realidade dos povos indígenas, pois conforme Garnelo e col. (2003, p. 80) há "incongruência entre a noção de representatividade genérica demandada pelo sistema de saúde e os modos tradicionais de legitimidade e representatividade de líderes indígenas”. À semelhança do processo de seleção dos AISs, as escolhas dos conselheiros indígenas também se dão com um forte referencial das lideranças e dos processos políticos locais. Esta situação, que deveria gerar uma multiplicidade de vozes representativas dos membros das comunidades, acabava na vocalização de interesses particulares, por exemplo: um conselheiro indígena questionou a legitimidade do que havia sido dito em reunião anterior por outros conselheiros indígenas da mesma comunidade. Para esse índio, "os conselheiros que falaram na reunião passada não conhecem a realidade e as dificuldades da área”, reportando-se ao fato de que eram infundadas as denúncias feitas sobre problemas gerados pelos gastos excessivos e sem resultados, uso indevido dos carros da saúde e política interna marcada pela interferência das lideranças.

O Condisi Insul era determinado pela dimensão burocrático-administrativa em detrimento da dimensão política: as questões discutidas eram em sua maioria operacionais, com a vocalização de denúncias e demandas individualizadas. Isso implicava em baixa capacidade dessa instância de influir no processo de participação e controle social (gestão, programação, execução e avaliação) ou mesmo de negociar interesses divergentes. Um conselheiro Kaingang expressou sua frustração com essa burocratização do processo: "Índio tem que respeitar a lei [referindo-se à sociedade não-indígena] e o povo sofre. Na prática é diferente."; para ele, parecia não fazer sentido "ficar atrás da mesa vendo a lei e o povo morrendo", concluindo que “o índio não pensa amanhã, pensa bem pertinho".

A dinâmica de funcionamento do Condisi, portanto, se traduzia em uma representatividade marcada pela institucionalização e pela burocratização do processo de participação e controle social e pela troca constante de conselheiros indígenas (tanto locais quanto distritais), apontada por um índio como um problema. Se por um lado, a rotatividade de membros dos Conselhos pode traduzir um maior exercício de- mocrático no âmbito da sociedade, por outro no caso indígena são poucos os índios que têm entendimento e domínio da estrutura burocrático-administrativa e das políticas de saúde. A troca ocorria sem que os conselheiros indígenas, de modo geral, tivessem a possibilidade de apreender o seu papel e conhecer a dinâmica da política e das ações em saúde.

\section{Processos de centralização}

A institucionalização e a burocratização apontadas acima refletiam em centralização dos processos decisórios, alijando os conselheiros, em especial os indígenas. A exemplo, o Condisi manifestou-se contra uma orientação dos coordenadores regionais da Funasa (orientação com o aval do Departamento de Saúde Indígena - Desai/Funasa/Brasília), que dizia não existir vínculo hierárquico com a chefia do distrito sediado em Florianópolis. Segundo os conselheiros, "isto repercute em decisões centralizadas dos próprios coordenadores sem prévia consulta aos conselhos locais e distritais".

Outro aspecto que enfatizava a centralização era a falta de interlocução entre o Conselho Distrital e os Conselhos Locais, citada tanto pelos conselheiros indígenas quanto pelos não-indígenas. Além da não articulação entre o Condisi e os Conselhos Locais, a falta de interlocução com a Comissão Intersetorial de Saúde Indígena (CISI), e, por conseqüência, com o Conselho Nacional de Saúde (CNS), também foi observada. Embora a CISI tenha como atribuições a análise de demandas e estratégias políticas para as ações em saúde indígena, bem como o subsídio ao CNS na tomada de decisões, a estrutura do fluxo de controle social (Garnelo e col., 2003, p.79) não contempla uma comunicação direta das deliberações dos Conselhos Distritais com a CISI e vice-versa. Some-se a isso o fato de que o sul do país nunca contou com representante indígena na CISI, explicando em parte, as dificuldades de se fazer chegar ao nível central solicitações e decisões do Condisi Insul.

A centralização também dizia respeito ao local das reuniões, sempre em Florianópolis. Mais de uma vez foi solicitado que as reuniões do Condisi fossem realizadas em municípios do DSEI que têm índios, visando aproximar os gestores municipais e melhorar o controle social; porém, o revezamento dos locais nunca foi respeitado pela Funasa e pela chefia do DSEI. 
As visitas dos conselheiros distritais às áreas indígenas e sua aproximação das lideranças indígenas (vistas como maneiras de descentralizar o poder) foram reivindicadas pelos conselheiros indígenas, para que os conselheiros conhecessem melhor a realidade e se sensibilizassem para o papel do Conselho Distrital e do controle social; contudo, isso não aconteceu.

Lançando um olhar mais amplo, é importante destacar o papel que vem assumindo o Fórum Permanente de Presidentes de Conselhos Distritais de Saúde Indígena. Criado em 2005, mas oficializado em 2006 (Brasil, 2006b), possui competências que se sobrepõem àquelas definidas para os Conselhos indígenas, o que poderá significar o deslocamento do processo de participação e de controle social pelas comunidades, centralizando-o em uma organização. Além disso, estando "a assessoria técnica e logística ao Fórum" (Brasil, 2006b, p. 3) a cargo da Coordenação de Apoio à Gestão e à Participação Social do Desai/Funasa, pode-se depreender uma maior hegemonia dessa instituição na participação indígena e no controle social.

\section{Capacitação}

O tema capacitação de conselheiros foi motivo de debates e solicitação em mais de uma reunião do Condisi. Como prioridade na capacitação, o "conhecimento das leis para não perder o controle". Segundo um índio, "para ser conselheiro tem que ser político." Isso nos leva a sugerir que a visão dos índios sobre a participação e o controle social é muito mais o exercício da política do que a realização de intervenções que influenciem a formulação, a execução e a avaliação das políticas públicas para o setor saúde.

Durante participação na IV Oficina de Saúde Indígena, durante o III Congresso Brasileiro de Ciências Sociais e Humanas em Saúde (Florianópolis, 2005), um representante indígena da CISI salientou que: Atualmente o movimento indígena reivindica DSEI autônomos; realização das capacitações; seleção dos profissionais de saúde pelos conselheiros; controle dos recursos repassados e dos incentivos hospitalares; que o Fórum Permanente de Presidentes dos Conselhos Distritais seja responsável pela capacitação dos conselheiros, visando autonomia do Controle Social. O controle social é a base da participação indígena, mas há aparente contradição entre institucionalização do controle social e sua liberdade de atuação, fato que resulta em menor poder de controle indí- gena sobre a gestão da saúde. Que capacitação é oferecida para os Conselheiros Locais? Com base em que necessidades? Como se ensina protagonismo, já que protagonismo é luta política, que está fora das capacitações? Atualmente se ensina a percorrer a burocracia, mas não se ensina a questioná-la. Enquanto o movimento indígena não tomar para si a responsabilidade pela capacitação dos Conselheiros, não haverá controle social.

A contundência da fala acima não encontra reflexos na realidade. O Desai/Funasa tem sido o responsável pela capacitação de multiplicadores indígenas para o controle social. Em 2003, em Curitiba, foi realizado o Seminário de Avaliação do Controle Social nos DSEIs, o qual apontou o perfil desses multiplicadores: entender de política de saúde pública e indígena, conhecer a realidade das comunidades que compõem o DSEI, saber ler e escrever, conhecer o movimento indígena de sua região, ser indicado pelo conselho local ou distrital, não fazer uso de bebida alcoólica, entre outros. Os conteúdos compreendiam desde histórico das políticas de saúde no Brasil (SUS, Conferências de Saúde), funções dos conselhos, até elaboração de projetos e planejamento de ações. Podemos concluir, portanto, que a incumbência da capacitação para o gestor, definindo o perfil dos conselheiros e a função dos conselhos, significa falta de autonomia para a participação indígena e o controle social.

Ainda avaliando o tema capacitação, os gestores vêm apontando como um dos principais empecilhos para a realização de capacitações (aqui podemos incluir também os AISs) a falta de recursos financeiros. Os conselheiros reforçaram que é importante que as capacitações estejam entre as prioridades dos Planos Distritais de Saúde e, portanto, incluídas nas metas orçamentárias do Distrito, à semelhança da prestação de serviços de saúde. É importante ressaltar que os poucos cursos que já haviam sido realizados foram viabilizados por captação de recursos em outras fontes governamentais, como o Projeto Vigisus.

Para finalizar a discussão sobre a participação e o controle social na saúde indígena, a nova configuração para os DSEIs no sul e sudeste brasileiro (Brasil, 2006a) provavelmente não alterará significativamente alguns dos problemas já verificados em relação ao Condisi Insul, quiçá poderá aprofundá-los: a abrangência territorial do novo DSEI Sul-Sudeste é 
maior do que os antigos DSEI Interior e Litoral Sul isoladamente; os Guarani, que antes tinham um Condisi específico (Condisi Litoral Sul), agora terão de compartilhar sua representação com outras etnias; o gestor mantém a centralização das decisões.

\section{Considerações Finais}

As pesquisas demonstram claramente que os princípios da atenção diferenciada, tão bem elaborados nos documentos oficiais, ainda não se tornaram uma realidade, seja na forma de participação da comunidade e controle social , seja na formação de equipes multiprofissionais para trabalhar em situações multiculturais.

Fica evidente a partir de pesquisas e de discussões com os gestores que ainda não há um consenso do que seja atenção diferenciada. Para os AIS significa o acesso a serviços primários separados e com qualidade, além da prioridade na atenção secundária e terciária, para os administradores e profissionais de nível superior trata da questão "cultural”, porém com pouca compreensão do que isso implica na prática. Os documentos da Funasa, seguindo a política da Organização Mundial da Saúde, indicam que o caminho é "articular" ou "integrar" as práticas tradicionais de cuidados à saúde.

Não está claro se os serviços de atenção primária devem articular-se com as práticas tradicionais ou integrar-se às elas. A primeira implica o reconhecimento da legitimidade dessas práticas, e a segunda indica a instrumentalização a partir do viés biomédico.

Os discursos que circulam no país em relação aos projetos de medicina tradicional indicam visões bastante diferentes ao propor "integrar", "articular", "resgatar" ou "estimular" as práticas de medicina tradicional. Enquanto alguns projetos procuram uma convivência harmônica com os especialistas tradicionais, muitos outros procuram identificar e instrumentalizar práticas tradicionais que podem ser testadas e verificadas pela biomedicina quanto à sua eficácia. Essa idéia mantém a biomedicina na posição hegemônica de julgar as terapias que devem ser estimuladas ou eliminadas, bem como a relação assimétrica entre as práticas e os especialistas.

As noções de cultura e medicina tradicional tendem a ser conceituadas no molde "museológico", procurando traços culturais, homogeneidade e integrida- de que não existem. Os profissionais não reconhecem que as fronteiras entre os serviços oficiais de saúde e as práticas das medicinas indígenas são permeáveis. As práticas de saúde com origem na cultura indígena e as da biomedicina não são as únicas tradições médicas no campo social e não operam como entidades distintas. As pesquisas em Santa Catarina têm indicado que as práticas de auto-atenção entre os povos indígenas são resultados da tomada de decisões para a busca de auxílio diante de uma pluralidade de sistemas terapêuticos acessíveis. A Igreja de Saúde, liderada por um xamã Kaingang, uma índia e uma liderança indígena, atendendo à população indígena e não-indígena, é um bom exemplo de que essas práticas podem ser híbridas (Oliveira, 1996). Esse caso não é o único e a dinamicidade das práticas de auto-atenção tem sido apontada em várias outras pesquisas, entre indígenas e não-indígena (Morgado, 1994; Garnelo, 2003; Menéndez, 2003).

É necessário reconhecer que o campo social da saúde é permeado por várias tradições e inovações nas práticas de auto-atenção e é mais bem conceituado como uma situação de "intermedicalidade" (Greene, 1998; Follér 2004). Assume-se que os saberes tradicionais são mais bem entendidos como práticas de autoatenção inseridas em um contexto dinâmico de intermedicalidade, que "se refere aos discursos e apropriações de conhecimentos, aos processos de hegemonia locais e globais, às negociações interculturais e à produção de medicinas híbridas" (Langdon, 2004, p. 48).

Não existe uma oposição a priori entre o sistema "tradicional" e a biomedicina. Observações têm demonstrado exatamente o contrário, ou seja, que os índios reinterpretam, re-significam e se apropriam de elementos e práticas da medicina ocidental (Langdon e MacLennan, 1979; Langdon e Rojas, 1991; Langdon, 1994; Morgado, 1994; Greene, 1998; Novaes, 1998; Diehl, 2001; Garnelo e Wright, 2001; Garnelo, 2003). A situação de intermedicalidade emerge na negociação de saberes e de forças de poder entre os atores sociais, sendo melhor pensar, portanto, as práticas de saúde nas comunidades indígenas como resultados de processos sócio-históricos e não de processos biológicos.

É de nosso entendimento que a articulação entre as práticas de saúde está sem possibilidade de realização no funcionamento atual do subsistema de saúde indígena e que freqüentemente o discurso é mora- 
lizante e revela preconceitos sobre as práticas de autoatenção da comunidade, sejam indígenas ou não. Para nós, a operacionalização da atenção diferenciada deve priorizar a garantia da participação política das comunidades indígenas em todo o processo de planejamento, execução, gestão e avaliação dos serviços; porém, nossas pesquisas apontam que a não preparação para o trabalho em contextos multiculturais, junto com as tendências de centralização, burocratização e institucionalização, impedem a efetivação dos processos participatórios, tanto nas EMSIs quanto nos Conselhos.

A formação ou a capacitação, seja de membros nãoindígenas das EMSIs ou dos AIS e conselheiros indígenas, é insuficiente. Atualmente, o problema maior é a falta de recursos ou de planejamento para a realização desses cursos, embora haja expressiva demanda para capacitação tanto por parte dos AISs quanto dos índios nos Conselhos. É difícil julgar a adequação do conteúdo dos cursos devido à escassa realização, mas uma das poucas avaliações aponta para estratégias didáticas inapropriadas (Garnelo, 2001). Nosso exame dos módulos para capacitação dos AISs, publicados na página eletrônica da Funasa (Brasil, 2005a, 2005b, 2005c, 2005d, 2005e, 2005f), indica que o conteúdo trata na maior parte de procedimentos e informações biomédicas e não de temas orientados para preparar os índios com a competência necessária para a participação no processo de democratização da saúde e atenção diferenciada.

Foi recorrente entre os AIS a falta de comunicação entre as comunidades e as EMSIs e a visão em nível local e distrital, já que os profissionais de saúde “não conhecem a realidade”. Esse problema também foi observado entre os conselheiros indígenas. Como demonstrado por outras análises sobre a implantação dos DSEIs (Athias e Machado, 2001; Varga e Adorno, 2001), o estabelecimento de muitos deles a partir de 1999 foi realizado rapidamente, sem a participação dos índios. Como apontam Varga e Adorno (2001), a manutenção da estrutura tradicional da Funasa, evidenciada pela verticalidade de suas tradicionais linhas de mando e tomadas de decisão, significou que não houve uma transformação do planejamento, da execução e da avaliação dos serviços de saúde.

Nossos dados indicam que de fato a situação estrutural não mudou. A operacionalização das ações em saúde e a condução das reuniões dos Conselhos são caracterizadas por processos burocrático-administrativos, que são pautados por hierarquização de papéis e hegemonias tradicionais. Os índios, ocupando somente o cargo de AIS ou de conselheiros e empregados pelas instituições envolvidas, têm papéis ambíguos entre interesses da comunidade e interesses de seus empregadores. Freqüentemente, as reuniões dos Conselhos pareciam mais uma reunião de trabalho dos funcionários das instituições gestoras e executoras, e não de um grupo com uma postura crítica. Há problemas sérios de representatividade no Conselho, já que nem todas as etnias tinham representação, as demandas e queixas tinham um caráter individualizado e não de interesses coletivos e parte significativa dos conselheiros (indígenas ou não) eram funcionários das instituições encarregadas das ações e serviços de saúde.

No caso dos AISs, eles não representam os saberes indígenas e não estão preparados para realizar um papel de mediação, ocupando um papel ambíguo sem reconhecimento como profissional em uma equipe hierarquizada, com tarefas bem definidas entre os membros.

Em ambos os casos, a realidade indica que os profissionais e outros não-indígenas envolvidos nesse processo continuam operando com uma práxis caracterizada por uma forte centralização e burocracia, sob a hegemonia do modelo biomédico, enquanto aos indígenas restam suas interpretações do que seja necessário para adequar suas ações e aproveitar as novas oportunidades oferecidas pelo sistema.

Apesar das considerações apontadas, o aumento do número de indígenas contratados como Agentes Indígenas de Saúde e a paridade de representação nos Conselhos são elementos importantes no processo de implantação do modelo de atenção à saúde indígena. O AIS e os conselheiros indígenas fazem parte da reivindicação central das organizações indígenas na constituição da política de saúde indígena, visando a mais participação nos serviços de saúde, seja no planejamento, na gestão, na avaliação ou no controle social. Há, porém, a necessidade de um olhar crítico sobre a operacionalização do subsistema e a organização burocrática e hierarquizada que permeia todas as relações, durante as interações dos membros (AIS ou não) da EMSI com os índios, ou durante as reuniões dos Conselhos. 


\section{Agradecimentos}

Agradecemos aos Agentes Indígenas de Saúde das Terras Indígenas Xapecó e Laklãnõ, Santa Catarina, por terem dedicado seu tempo às pesquisas; aos profissionais das Equipes Multiprofissionais de Saúde Indígena de ambas as Terras Indígenas, bem como aos gestores da Fundação Nacional de Saúde e dos municípios de Ipuaçu e de Entre Rios.

Nossos especiais agradecimentos ao Flávio Braune Wiik, à Raquel Paiva Dias-Scopel, à Bárbara F. Bustos e ao Philippe H. A. Oliveira, que participaram em várias fases da pesquisa realizada em 2004 e à Fundação de Apoio à Pesquisa Científica e Tecnológica do Estado de Santa Catarina (Fapesc), pelos recursos financeiros concedidos à pesquisa realizada em 2004, por meio do Edital 003/2003, que contou ainda com a colaboração da Organização das Nações Unidas para a Educação, a Ciência e a Cultura (Unesco) e do Ministério da Saúde.

\section{Referências}

ATHIAS, R.; MACHADO, M. A saúde indígena no processo de implantação dos distritos sanitários: discursos antropológicos e médicos. Cadernos de Saúde Pública, Rio de Janeiro, v. 17, n. 2, p. 425-431, 2001.

BITTENCOURT, M. et al. Acre, Rio Negro e Xingu: a formação indígena para o trabalho em saúde. São Paulo: Associação Saúde sem Limites, 2005.

BRASIL. Fundação Nacional de Saúde. Formação de agentes indígenas de saúde: proposta de diretrizes. Brasília, DF, 1996.

BRASIL. Decreto n 3.156 , de 27 de agosto de 1999. Dispõe sobre as condições de assistência à saúde dos povos indígenas. Diário Oficial da União, Brasília, DF, 28 ago. 1999a. Seção 1, p. 37.

BRASIL. Lei no 9.836/99, de 23 de setembro de 1999. Estabelece o subsistema de atenção à saúde indígena no âmbito do SUS. Diário Oficial da União, Brasília, DF, 24 set. 1999b. Seção 1, p. 1.
BRASIL. Ministério da Saúde. Portaria nº 1.163, de 14 de setembro de 1999. Dispõe sobre as responsabilidades na prestação de assistência à saúde dos povos indígenas, no Ministério da Saúde e dá outras providências. Diário Oficial da União, Brasília, DF, 15 set. 1999c. Seção 1, p. 33.

BRASIL. Fundação Nacional de Saúde. Política nacional de atenção à saúde dos povos indígenas. 2. ed. Brasília, DF, 2002.

BRASIL. Ministério da Saúde. Conselho Nacional de Saúde. Resolução n. 333, de 4 de novembro de 2003. Brasília, DF, 2003.

BRASIL. Ministério da Saúde. Portaria $n^{0}$ 7o/GM, de 20 de janeiro de 2004. Aprova as diretrizes da gestão da Política Nacional de Atenção à Saúde Indígena. Brasília, DF, 2004. Disponível em: <http:// www.funasa.gov.br/Web\%2oFunasa/Legis/pdfs/ portarias_m/pm_70_2004.pdf >. Acesso em: 29 jan. 2007.

BRASIL. Fundação Nacional de Saúde. Formação inicial para agentes indígenas de saúde: módulo introdutório. Brasília, DF, 2005a.

BRASIL. Fundação Nacional de Saúde. Educação profissional básica para agentes indígenas de saúde: módulo promovendo a saúde e prevenindo parasitoses intestinais e doenças de pele. Brasília, DF, 2005b.

BRASIL. Fundação Nacional de Saúde. Formação inicial para agentes indígenas de saúde: módulo promovendo a saúde do adulto e atendendo urgências. Brasília, DF, 2005c.

BRASIL. Fundação Nacional de Saúde. Formação inicial para agentes indígenas de saúde: módulo promovendo a saúde e prevenindo doenças endêmicas. Brasília, DF, 2005d.

BRASIL. Fundação Nacional de Saúde. Educação profissional básica para agentes indígenas de saúde: módulo promovendo a saúde da mulher, da criança e a saúde bucal. Brasília, DF, 2005e.

BRASIL. Fundação Nacional de Saúde. Formação inicial para agentes indígenas de saúde: módulo promovendo a saúde e prevenindo DST/Aids. Brasília, DF, 2005f. 
BRASIL. Ministério da Saúde. Portaria no 1.810 , de 3 de agosto de 2006. Define as transformações dos Distritos Sanitários Especial Indígena (DSEI). Brasília, DF, 20o6a. Disponível em: <http:// www.funasa.gov.br/Web\%2oFunasa/Legis/pdfs/ portarias_m/pm_1810_20o6.pdf>. Acesso em: 29 jan. 2007 .

BRASIL. Ministério da Saúde. Portaria nº 644, de 27 de março de 20o6. Institui o Fórum Permanente de Presidentes dos Conselhos Distritais de Saúde Indígena. Brasília, DF, 20o6b. Disponível em: <http:// www.funasa.gov.br/Web\%2oFunasa/Legis/pdfs/ portarias_m/pm_644_20o6.pdf>. Acesso em: 12 fev. 2007 .

BRASIL. Ministério da Saúde. Portaria no 204, de 29 de janeiro de 2007. Regulamenta o financiamento e a transferência dos recursos federais para as ações e os serviços de saúde, na forma de blocos de financiamento, com o respectivo monitoramento e controle. Brasília, DF, 2007. Disponível em: <http:// www.conasems.org.br/Doc_diversos/ Portaria_204.pdf>. Acesso em: 12 fev. 2007.

COHN, A. Estado e sociedade e as reconfigurações do direito à saúde. Ciência \& Saúde Coletiva, Rio de Janeiro, v. 8, n. 1, p. 9-18, 2003.

CRÉPEAU, R. A prática de xamanismo entre os Kaingang do Brasil meridional: uma breve comparação com o xamanismo Bororo. Horizontes Antropológicos, Porto Alegre, ano 8, n. 17, p. 113-130, 2002.

DIEHL, E. E. Entendimentos, práticas e contextos sociopolíticos do uso de medicamentos entre os Kaingáng (Terra Indígena Xapecó, Santa Catarina, Brasil). 2001. Tese (Doutorado em Saúde Pública) Escola Nacional de Saúde Pública, Fundação Oswaldo Cruz, Rio de Janeiro, 2001.

DIEHL, E. E. et al. Financiamento e atenção à saúde no Distrito Sanitário Especial Indígena Interior Sul. In: COIMBRA JR, C. E. A.; SANTOS, R. V.; ESCOBAR, A. L. (Org.). Epidemiologia e saúde dos povos indígenas no Brasil. Rio de Janeiro: Fiocruz, 2003. p. 217-234.

ERTHAL, R. M. C. A formação do agente de saúde indígena Tikúna no Alto Solimões: uma avaliação crítica. In: COIMBRA JR, C. E. A.; SANTOS, R. V.;
ESCOBAR, A. L. (Org.). Epidemiologia e saúde dos povos indígenas no Brasil. Rio de Janeiro: Fiocruz, 2003. p. 197-215.

FOLLÉR, M. L. Intermedicalidade: a zona de contato criada por povos indígenas e profissionais de saúde. In: LANGDON, E. J.; GARNELO, L. (Org.). Saúde dos povos indígenas: reflexões sobre antropologia participativa. Rio de Janeiro: ContraCapa: ABA, 2004. p. 129-148.

GARNELO, L. Projeto Rede Autônoma de Saúde Indígena: uma experiência de educação e comunicação em saúde indígena. In: VASCONCELOS, E. M. (Org.). A saúde nas palavras e nos gestos: reflexões da Rede Educação Popular e Saúde. São Paulo: Hucitec, 2001. p. 237-260.

GARNELO, L. Poder, hierarquia e reciprocidade: saúde e harmonia entre os Baniwa do Alto Rio Negro. Rio de Janeiro: Fiocruz, 2003.

GARNELO, L.; WRIGHT, R. Sickness, healing and health services: social representations, practices and demands among the Baníwa. Cadernos de Saúde Pública, Rio de Janeiro, v. 17, n. 2, p. 273-284, 2001.

GARNELO, L.; MACEDO, G.; BRANDÃO, L. C. Os povos indígenas e a construção das políticas de saúde no Brasil. Brasília, DF: OPAS, 2003.

GARNELO, L.; SAMPAIO, S. Bases sócio-culturais do controle social em saúde indígena: problemas e questões na região norte do Brasil. Cadernos de Saúde Pública, Rio de Janeiro, v. 19, n. 1, p. 311-317, jan./fev. 2003 .

GARNELO, L. et al. Medicina tradicional Baniwa, organizações indígenas e a antropologia da intervenção. In: LANGDON, E. J.; GARNELO, L. (Org.). Saúde dos povos indígenas: reflexões sobre antropologia participativa. Rio de Janeiro: ContraCapa: ABA, 2004. p. 171-194.

GREENE, S. The shaman's needle: development, shamanic agency, and intermedicality in Aguaruna Lands, Peru. American Ethnologist, Washington, DC, v. 25 , n. 4 , p. $634-658,1998$.

HAVERROTH, M. Kaingang: relação entre classificação das plantas e organização social. Revista de Divulgação Cultural, Blumenau, ano 20, n. 64, p. 32-47, 1998. 
KRENAK, A. A. G. O. et al. Encontro aponta soluções para a proteção da saúde do índio: conclusões da Conferência Nacional de Proteção à Saúde do Índio. Saúde em Debate, Rio de Janeiro, p. 6o-61, jan. 1988. Edição especial.

LANGDON, E. J. Representações de doença e itinerário terapêutico entre os Siona da Amazônia Colombiana. In: SANTOS, R. V.; COIMBRA, C. (Org.). Saúde e povos indígenas. Rio de Janeiro: Fiocruz, 1994. p. 115-142.

LANGDON, E. J. Uma avaliação crítica da atenção diferenciada e a colaboração entre a antropologia e profissionais de saúde. In: LANGDON, E. J.; GARNELO, L. (Org.). Saúde dos povos indígenas: reflexões sobre antropologia participativa. Rio de Janeiro: ContraCapa: ABA, 2004. p. 33-51.

LANGDON, E. J.; MACLENNAN, R. Western biomedical and Sibundoy diagnosis: an interdisciplinary comparison. Social Science and Medicine, Oxford, v. 13B, p. 211-220, 1979.

LANGDON, E. J.; ROJAS, B. G. Saúde: um fator ignorado numa situação de mudança rápida: a situação da área indígena Ibirama (SC). Boletim de Ciências Sociais, Florianópolis, n. 51, p. 65-89, 1991.

LANGDON, E. J. et al. A participação dos agentes indígenas de saúde nos serviços de atenção à saúde: a experiência em Santa Catarina. Cadernos de Saúde Pública, Rio de Janeiro, v. 22, n. 12, p. 2637-2646, dez. 2006.

MACHADO, F. A. Participação social em saúde. In: CONFERÊNCIA NACIONAL DE SAÚDE, 8., 1986, Brasília. Anais... Brasília, DF: Ministério da Saúde, 1986. p. 299-305.

MARINHO, G. L. Agentes indígenas de saúde de Rondônia: um estudo etnográfico. Porto Velho: Universidade de Rondônia, 20o6. Relatório final.

MARQUES, I. M. S. F. A política de atenção à saúde indígena: implementação do distrito sanitário especial indígena de Cuiabá - Mato Grosso. 2003. Dissertação (Mestrado em Saúde Pública) - Escola Nacional de Saúde Pública, Fundação Oswaldo Cruz, Rio de Janeiro, 2003.
MENDONÇA, S. B. M. O agente indígena de saúde no Parque Indígena do Xingu: reflexões. In: BARUZZI, R.; JUNQUEIRA, C. (Org.). Parque Indígena do Xingu: saúde, cultura e história. São Paulo: Unifesp: Terra Virgem, 2005. p. 227-244.

MENÉNDEZ, E. Modelos de atención de los padecimientos: de exclusiones teóricas y articulaciones prácticas. Ciência \& Saúde Coletiva, Rio de Janeiro, v. 8, n. 1, p. 185-208, 2003.

MORGADO, P. O pluralismo médico Wayana-Aparai: a intersecção entre a tradição local e a global. Cadernos de Campo, São Paulo, n. 4, p. 41-70, 1994.

NOVAES, M. R. de. Interpretação da doença e simbolismo terapêutico entre os Wari de Rondônia, Brasil. Revista de Divulgação Cultural, Blumenau, ano 20, n. 64, p. 68-75, 1998.

NUNES, M. de O. et al. O agente comunitário de saúde: construção da identidade desse personagem híbrido e polifônico. Cadernos de Saúde Pública, Rio de Janeiro, v. 18, n. 6, p.1639-1646, 2002.

OLIVEIRA, L. S. S. Formação e inserção institucional de agentes indígenas de saúde no Sistema Único de Saúde: um estudo de possibilidades. 2002. Tese (Doutorado em Saúde Pública) - Faculdade de Saúde Pública, Universidade de São Paulo, São Paulo, 2002.

OLIVEIRA, L. S. S. O agente indígena de saúde do Parque Indígena do Xingu: perspectivas de formação e trabalho. In: BARUZZI, R.; JUNQUEIRA, C. (Org.). Parque Indígena do Xingu: saúde, cultura e história. São Paulo: Unifesp: Terra Virgem, 2005. p. 247-257.

OLIVEIRA, M. C. Os especialistas Kaingáng e os seres da natureza: curadores da aldeia Xapecó: oeste de Santa Catarina. Florianópolis: FCC, 1996.

OLIVEIRA, M. C. Percepção corpórea e a questão da dieta em momentos de liminaridade: o exemplo Kaingáng. In: OFICINA MACRORREGIONAL DE ESTRATÉGIA, PREVENÇÃO E CONTROLE DAS DST/ AIDS PARA AS POPULAÇÕES INDÍGENAS DAS REGIÕES SUL E SUDESTE E DO MATO GROSSO DO SUL, 1., 1997, Londrina. Anais... Londrina:

Coordenação Nacional de DST/AIDS: Programa Municipal para DST/AIDS/ALIA, 1997. p. 69-78. 
ROSA, R. R. G. Os Kujà são diferentes: um estudo etnológico do complexo xamânico dos Kaingang da terra indígena Vontouro. 2005. Tese (Doutorado em Antropologia) - Universidade Federal de Rio Grande do Sul, Porto Alegre, 2005.

SANTOS, S. C. Os índios Xokleng: memória visual. Florianópolis: UFSC: Univali, 1997.

VARGA, I.; ADORNO, R. C. F. Terceirizando a indianidade?: sobre a política nacional de saúde para os povos indígenas aos 500 anos. Revista de Direito Sanitário, São Paulo, v. 2, n. 1, p. 9-26, 2001.

VEIGA, J. As religiões cristãs entre os Kaingang: mudança e permanência. In: WRIGHT, R. M. (Org.). Transformando os Deuses II: igrejas evangélicas, pentecostais e neopentecostais entre os povos indígenas no Brasil. Campinas: Unicamp, 2004. p. 169-198.
WIIK, F. B. Contato, epidemias e corpo como agentes de transformação: um estudo sobre a AIDS entre os índios Xokléng de Santa Catarina, Brasil. Cadernos de Saúde Pública, Rio de Janeiro, v. 17, n. 2, p. 397406, 2001.

WIIK, F. B. O evangelho transformado: apropriações Xokleng (Jê) do cristianismo pentecostal. In:

WRIGHT, R. M. (Org.). Transformando os Deuses II: igrejas evangélicas, pentecostais e neopentecostais entre os povos indígenas no Brasil. Campinas:

Unicamp, 2004. p. 141-168. 